\title{
An Introduction to Business Problem-Solving and Decision-Making
}

\author{
John Beachboard \\ Idaho State University \\ Pocatello, Idaho, USA
}

\author{
Kregg Aytes \\ Montana State University \\ Bozeman, Montana, USA \\ aytekreg@isu.edu
}

\begin{abstract}
This essay was created to provide content for use in core IS business courses which emphasize the teaching of Excel (or any type of spreadsheet or analytic software). The authors have observed that the typical textbooks used in such courses jump directly into teaching the mechanics of the software paying relatively little attention to the context in which these tools will be used. This essay attempts to remedy that deficiency by providing an overview of business decisionmaking without requiring our students to purchase another book. Accordingly, the target audience for this essay is undergraduate students. We submitted this essay to InSITE hoping to receive substantive comments that could be used to improve the paper.
\end{abstract}

Keywords: decision-making, problem-solving, cognitive biases, groupthink

\section{Introduction}

The day-to-day work of business professionals requires solving problems (or assessing opportunities) and making decisions. These activities often occur in a cloud of uncertainty, where there is no absolutely clear way to develop or choose among alternatives. Who is the best candidate to hire for this job? Should the business invest in developing product A or product B? Should we invest in a customer relationship management system? Where should we spend more of our advertising budget? Business professionals are called upon to make a countless number of decisions. Some of those decisions can profoundly impact business and personal success.

Without being unduly negative, we need to understand that decision-making can be very problematic. You don't have to take our word on this; there are some well written books that describe the dramatic consequences of "expert" decision-making gone awry. We'll briefly outline a few examples, but strongly encourage you to read one or more of the references.

- Allan McDonald and James Hansen (2009) in Truth, Lies, and, O-rings: Inside the Space shuttle Challenger Disaster give an insider's account of the 1986 Challenger disas-

Material published as part of this publication, either on-line or in print, is copyrighted by the Informing Science Institute. Permission to make digital or paper copy of part or all of these works for personal or classroom use is granted without fee provided that the copies are not made or distributed for profit or commercial advantage AND that copies 1) bear this notice in full and 2) give the full citation on the first page. It is permissible to abstract these works so long as credit is given. To copy in all other cases or to republish or to post on a server or to redistribute to lists requires specific permission and payment of a fee. Contact Publisher@InformingScience.org to request redistribution permission. ter. In the book, Allan McDonald, a management engineer for MortonThiokol, details the events leading up to the fateful decision to launch the Challenger launch despite the warnings of knowledgeable engineers who recommended against the proposed cold weather launch. Cold weather caused the O-rings used in the booster to become brittle allowing hot gases to es- 
cape, ultimately resulting in an explosion that destroyed the Challenger Space shuttle and killed the seven astronauts on board.

- 1996 Mount Everest tragedy as reported by John Krakauer (1999) in Into Thin Air: A Personal Account of the Mount Everest Disaster describes how two commercial expedition teams led by highly experienced climbers failed to follow their own pre-established turn-back rules - failures that resulted in the death of the two leaders as well as three other team members. A turn-around time is when the team needs to start back down the mountain, even if the summit has not been reached. Firm turn-around times are established to ensure that climbers do not have to climb back down in the dark. The tragedy occurred when one of the climbing teams continued on to the summit climbing past the designated turn-back time. The team was caught in a storm while climbing down in the dark and could not find its base camp. A further death resulted when the leader of the second climbing team attempted to aid in the rescue of the first team.

- If you believe that economically motivated, numbers-driven business professionals are unlikely to make these types of decision errors, Paul Carroll and Chunka Mui (2008) in Billion Dollar Lessons: What You Can Learn from the Most Inexcusable Business Failures of the Last 25 Years describe numerous executive-level decision-making failures revolving around major corporate mergers and acquisitions. Over the 25 year period examined, they document hundreds of failed mergers and acquisition decisions that resulted in $\$ 380$ billion in write-offs and the wholesale destruction of shareholder value.

Only the more dramatic decision-making failures get reported in the news and history books, but the same types of decision-failures occur on a daily basis.

Consequently, the purpose of this essay is to introduce you to methods and techniques that will help you solve problems and make decisions. Of course, no technique or set of techniques can be guaranteed to reliably result in correct decisions. We live in a world of uncertainty; we cannot perfectly predict all outcomes and possible consequences of our decisions. Rather, the presentation of decision- and behavioral- science techniques below is simply intended to:

1. Provide a thorough enough introduction to decision-making strategies to help you improve your decision-making ability, i.e., your chances of making successful decisions.

2. Allow you to demonstrate that a defensible decision-making strategy or process was used, even if your decisions turn out to be wrong.

3. Introduce you to relevant fields of study that you may want to explore in the future to improve your decision-making performance.

\section{Problems, Opportunities and Decisions}

Since we are in an educational environment, we need to take a little time to define our terms... because in the "real world" usage and definitions can be a bit slippery.

Decision-making is directly associated with selecting one course of action among two or more possible alternatives. Decision-making is driven by a desire to solve problems or exploit opportunities. A problem refers to some type of event that requires a response to avoid a negative consequence. Conversely an opportunity is an event or situation where a response is required to make something desirable happen. Maybe nothing bad will happen if we do nothing, but our inaction might cause us to miss out on something we want. In this essay we use the term "problems" to generically refer to both problems and opportunities. (Think about it this way. If you miss out on a good thing, that's a bad thing. Right?) Since there is almost always a choice between doing nothing and doing something, we are constantly making decisions. 
The next section presents barriers to good decision-making. After describing some of these barriers, we present decision-making techniques aimed at alleviating the problems discussed.

\section{The Psychology and Sociology of Decision-Making}

Who would expect to read about psychology and sociology in an IT class? Ha! Trick question, this is a business class, but still... it turns out that a rational model of decision-making has historically informed the study of economics, finance and general management science. However, when researchers studied how decisions were really made, they found that the rational model did not hold up too well. There are problems with the "rational" model. The rational model assumes the decision-maker has access to all the information required to make the decision. The rational model also implies decision-makers have a relatively stable set of preferences (economists use the term, "utilities"). The idea is that "rational" decision-makers are able to accurately assess costs and benefits and choose alternatives which maximize benefits while minimizing costs. This sounds easy enough, except for the fact that in many circumstances, we don't have all the information that we need, some of the information that we do have is not that good, we ignore some of information that we do have, and it turns out that our preferences are not necessarily stable. Much of recent decision-making theory deals with how we as individuals and as members of larger groups process information and deal with uncertainty (Kahneman, 2011).

In addition to dealing with uncertainty, it turns out there are psychological and sociological factors that can influence how we use or fail to use information that is available as well as how we deal with uncertainty.

\section{Cognitive Biases}

Adhering to a rational decision-making model is even tougher than the problem of uncertainty suggests. As humans, we seem to be programmed with a set of decision-making shortcuts, cognitive biases, that cause our decision-making to depart substantially from the rational model. Cognitive biases can affect experts as well as novice decision-makers, and we need to understand their potentially damaging effects. Following are brief explanations of several cognitive biases that have been observed in the business world:

- Over-confidence bias. Research and experience have demonstrated that a majority of us tend to be over confident. For example if you ask members of a class to estimate whether they are above average in some particular skill or knowledge, well over half are likely to claim that they are. Perhaps the class is full of exceptional individuals, but given a fair sample, logic dictates that no more than half of the students can actually be above average. Hubbard (2010) cites numerous examples of experts' overconfidence and offers calibration training to help experts improve their estimates. Carroll and Mui (2008) argue that over-confidence most certainly contributed to poor decisions leading to the large losses identified in their study.

- Sunk-cost and escalation of commitment effects. These cognitive biases refer to an unwillingness to give up on a course of action once a large amount of effort or resources have been invested. Economic theory says that once the money or time has been spent, it's gone and you can't get it back. Your future investment in a particular course of action should be based on the probability of success based on future investments rather than considering what was already expended. But the psychological pain associated with having to acknowledge the loss makes it difficult for us to make an unbiased calculation regarding our future chances of success or failure. When we continue to pursue a course of action where there is little or no chance of success, this is referred to as "escalation of commitment." M. Lynn Markus and Mark Keil (1994) describe a real-world case where 
a company continued to invest in an IT project despite the intended users' refusal to use the application.

- Recency and availability effects. These two biases refer to our tendency to rely more heavily upon recent and readily available information. The problem is that the most recent and most available information is not necessarily the best information to use in making some decisions. Roberto (2005) discusses the problem in his analysis of the Everest example. The expert climbers leading the teams had developed their experience over the previous ten years prior to their climb. Unfortunately, the weather on Everest during those ten years had been mild relative to Mount Everest's historical weather patterns. Since the team leaders had not personally experienced the worst kinds of weather that Everest could offer, they did not fully appreciate the risks they were taking. Had the leaders experienced poor weather-related climbing conditions, they might have been more reluctant to ignore their own turn-back rules.

- Confirmation bias. Confirmation bias refers to our tendency to gather and rely on information that confirms our pre-existing beliefs and ignore or discount information that conflicts with those beliefs. Carroll and Mui (2008) described the merger of two insurance companies, Unum and Provident. The expectation for the merger was that the combined companies would achieve greater market power and reduce costs. Company executives believed they would be able to raise prices on an important set of insurance products by fourteen percent. Instead, they were only able to raise prices by seven percent and that was achieved with a loss of market share. Carroll and Mui argue that the executives believed what they wanted to believe, discounting the probable actions of their customers and competitors. Five years after the merger the combined companies' stocks had lost two thirds of their market value.

- Anchoring bias. The anchoring bias concerns our tendency to allow an initial estimate or even some irrelevant number to anchor or distort our subsequent estimates. We think it strange that simply writing down a number such as the last four digits of our telephone or social security numbers could influence our estimates on almost any subject (e.g., the length of the Nile River). But experiment after experiment has demonstrated that larger phone numbers correlated with larger estimates and lower numbers correlated with lower estimates. Research has provided evidence that business professionals will become anchored to their best estimates and underestimate confidence intervals surrounding those estimates (Hubbard, 2010).

There are additional cognitive biases (e.g., framing, illusory correlation, egocentrism), but the above psychological characteristics are sufficient for our purposes. And in case these biases haven't depressed you enough about your individual rationality, we find that the sociology of groups may further diminish our decision-making ability.

\section{Groupthink}

It turns out that two or more heads are not always better than one. The issue that concerns us here is groupthink, "a mode of thinking that people engage in when they are deeply involved in a cohesive in-group, when the members' strivings for unanimity override their motivation to realistically appraise alternative courses of action" (Janis 1982). Can we say that more clearly? How about, groupthink occurs when individual members fail to give their own opinion because they think it differs from their perception of the group's opinion and they want to avoid conflict.

It probably seems obvious, but the purpose of groups is to accomplish tasks that are beyond the capabilities of individuals working independently. To be truly successful, a group should be able to outperform the individual efforts of its best members working alone. If the group turns in a 
poorer solution, we say that there has been a group process loss, undermining the reason for the group's existence.

Researchers have offered a variety of factors that may contribute to process loss. Groups experiencing groupthink may:

- Poorly analyze problems by jumping too quickly to problem definitions and then closing off further debate

- Fail to identify and consider a sufficient set of alternative solutions to the problem

- Discount or ignore risks associated with the group's preferred alternative

- Limit its information search to focusing primarily on the collection of information that confirms its pre-existing definition of the problem and preferred alternative

- Fail to re-examine previously rejected alternatives even when new information is received that brings into question the group's original decision

- Fail to plan for contingencies if the chosen alternative does not work

Groupthink is associated with teams, groups, or committees operating under pressure or in highly competitive environments. Symptoms of groupthink include:

- The group's feeling superior to rival groups and maintaining negative stereotypes of rival groups

- The group's ignoring or rationalizing away information in conflict with its position

- The group's believing it has reached unanimous agreement without seeking to verify that

- The group's pressuring individuals who question the group position

- Group members self-censoring their opinions to avoid conflict or group sanctions

- Group member's assuming the role of "mind guards" and actively keeping the group from seeing information that contradicts the group position

When viewed together, you can see that cognitive biases and groupthink behaviors can be mutually reinforcing. An individual's tendency to filter undesirable information can be magnified if he or she feels that acknowledging such information will hurt group harmony. The group's refusal to re-evaluate its previous decisions aligns with the escalation-of-commitment bias.

The bottom line is that business professionals face a scary set of psychological and sociological pressures that can undermine their ability to make rational business decisions. We have only touched on these issues here. We encourage you to carefully consider these issues because the adverse consequences of cognitive biases and groupthink can dramatically impact business's performance as well as the quality of your work life. We discuss these issues in this course because information technology can contribute little to improving decisions if these forces are strongly in play.

\section{Developing an Effective Problem-Finding and Decision-Making Strategy}

No decision-making method can completely correct for the individual and group biases described above just as no technique can eliminate uncertainty. Perfect objectivity and complete scientific rationality might well be unattainable, but in most cases we can employ decision-making techniques that improve our overall decision performance over time. 
The following subsections draw upon research in critical thinking and decision-making to offer suggestions for creating an effective decision-making process. A key assumption informing the following recommendations is that problem-solving and decision-making need to be viewed as ongoing "processes" rather than as unique "events." We caution you that our description of the decision-making process will necessarily be linear (step-by-step). See the decision-making process model at Figure 1.

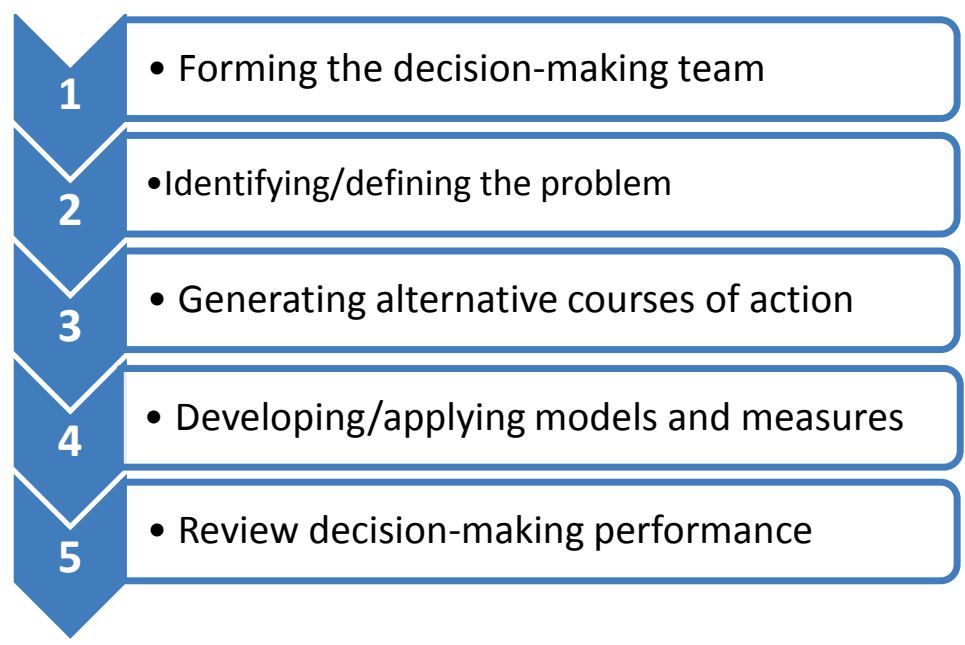

Figure 1. Decision-making Process Model

There is logic in the order of activities presented. But in practice, you need to recognize that the order is not firm. For example, step 1 calls for assembling the decision-making team. But putting together the appropriate decision-making team assumes some understanding of the problem to be solved (step 2). Consequently, the analysis of the problem area by the team may reveal a need to change the team. In short, we want a process that allows for learning to occur. Such learning may require the team to revisit earlier steps in the process or revise earlier decisions made in formulating the overall decision. The following sections describe what should generally occur in each step.

\section{Step 1. Assembling the team and creating an environment for achieving group success}

It probably appears obvious that an early step must be to decide who will be responsible for making the decision and whether that individual will require help or not. But we want to state the obvious because assembling the right team is critical to the success of the effort. Issues to consider in assembling an effective team include:

- Select participants with knowledge and skills relevant to the problem domain. Certainly this will include functional specialists but might also entail specialists in information search, quality assurance, laws and regulations, human resources, experimental design, decision science or statistics. Having a diverse set of knowledge, skills, and perspectives can help prevent groupthink and result in more creative decisions (Roberto, 2005).

- Set up rules and procedures for team conduct which formally notifies all team members that their full participation is permitted and expected despite status differences that may exist among team members. You do not want debate cut off because team members perceive that a high status member has already made up his or her mind. Sample procedures might include: 
- Using brainstorming techniques where criticism of ideas is prohibited while initial ideas are being suggested.

- Designating a "devil's advocate" whose role is to rigorously challenge team decisions and act as a very loyal opposition. The devil's advocate needs to be particularly sensitive to evidence indicating the presence of cognitive biases- or group think-type behaviors outlined above.

- Establishing rules for determining when consensus has been achieved and how decisions will be made when complete consensus cannot be achieved.

- Determining criteria for revisiting previous decisions when new information appears.

- Establishing criteria for calling on outside assistance to facilitate group decisionmaking.

- In summary, the idea is to set up rules that support creative conflict and establish procedural legitimacy (fair or socially accepted procedures).

- Ensure the team is provided with resources, particularly time, required to properly address the assigned issue.

\section{Step 2. Finding the problem}

Too often the decision-making literature presents the process as beginning with the "problem" already identified. Yet, the most critical element of the decision-making process is clear identification of the problem. Businesses managers can be prone to offering solutions for perceived problems before they have taken the time to understand what those problems really are. Certainly, there are times when decisive and immediate decisions are required. But more often than not, it is better to take a little time to aim before pulling the trigger.

The previous reading introducing systems thinking and business processes was intended to help you identify problems and opportunities. We want to expand on some of those ideas in this section. Often, what we perceive as the problem may be a symptom of an underlying problem that needs to be solved. For example, a business might identify its failure to get the desired level of repeat business as a problem. We may have intuitions about this problem: our prices are too high, our sales people are too surly, or our customers just don't appreciate what a good deal we are offering. But we need to understand, hopefully with solid evidence, our customers' behavior before launching an expensive solution to the repeat business problem.

A useful way to address the problem definition issue is to apply the "Five Whys" method originated at Toyota and widely used in Six Sigma (quality improvement) initiatives. The logic driving this technique is to ensure that you have identified the root cause of the problem that you are trying to solve. The technique is simple in theory but takes knowledge and discipline to effectively execute. A call center example follows:

- A clear description of the problem as originally understood (e.g., the firm is fail to get expected repeat business). The first why is, "why is this occurring?"

- We then propose the most likely explanation for the problem as observed (e.g., our phone ordering process may be too complicated; not only are we not seeing repeat business, but we have noticed an increasing number of hang-ups before orders are completed). So then we ask, why do we think we are experiencing hang-ups before order completion?

- After studying when and where the hang-ups are occurring, we might propose that a problem exists in the automated menu system or perhaps with the call center operators 
processing the calls. We notice a definite increase in our call handling times. Well, why is that occurring?

- We just moved our call center to India; perhaps it is a language or training problem. Or perhaps the phone lines are of poor quality and phone calls are being dropped. No, we checked that out and the operators and phone lines appear to be performing well for other lines of business. We need to dig in further. It turns out that entering orders into our online processing system is taking a long time. It does not appear to be a problem of operator training; the database is running really slowly at times. Why is the database running slowly?

- We are serving about the same number of customers yet input/output (the computer reading data to and from its hard drives) on are primary server has dramatically increased slowing database performance. Why has the amount of input/output increased? It turns out that the database application was upgraded and it had a bug in it that resulted in the increased input/output.

Management determined that there was a problem with the order processing system. Operators were taking nine minutes to process orders that had previously been processed in less than three minutes. They did not immediately start firing its operators, they took more time to investigate and learn the root cause of the problem.

Again, the object of the five whys exercise is to understand the root cause of the problem and not waste time addressing symptoms. Implicit in this effort is the development of a mental model of how the process or system is supposed to work. We use the systems and process thinking tools, introduced in the previous reading, to help build this mental model. If you don't understand how things are supposed to work, it will be pretty difficult to figure out what is going wrong. Then after you build the mental model to help you understand the problem, that model becomes the basis for developing a more explicit decision model (described below).

Don't be fooled by the call center example. It may look simple after the fact, but working your way through the various steps can be difficult. The causes may not always be so apparent; obtaining hard data required to test our hypotheses may be difficult, expensive and sometimes impossible.

We close this section with several observations pertaining to problem-finding steps:

1. If you don't ask the right questions, you can't get the right answers. Problem analysis takes an inquiring mind capable of combining intuitive (creative?) and analytic thinking.

2. You want to use evidence, not just opinions, in answering the why question; you need to maximize direct observation and minimize the need to draw inferences that cannot be supported by data.

3. The individual and group biases discussed above can infect the problem-finding step. Participants may not be willing to raise issues that might reflect poorly on themselves or their groups. The problem-finding process needs to focus on identifying problems, not assigning blame. Participants need to be secure that they will not be punished for being critical.

Perhaps we exaggerate when we offer the quote, "A problem well stated is a problem half solved" (Charles Kettering, quoted in Hubbard, 2010); but we don't think so. Developing accurate, well defined problem statements moves you down the path to more reliable decisions. 


\section{Step 3. Generating alternative courses of action}

Based on our understanding of the problem, we typically want to generate alternative solutions. This is fundamentally a creative process. Activities such as "brainstorming" are often used at this stage. While the topic merits more discussion than can be provided here, there are a few things to keep in mind that can help generate creative alternatives:

- Bring a fresh set of eyes to examine the problem. People new to the problem are not as bound by the same lines of thinking as those that have struggled with the problem for a long time.

- Defer judgment on new ideas. Do not dismiss potential alternatives prematurely; good solutions often seem inappropriate at first glance.

- Generate large quantities of alternatives. Research has consistently shown that more ideas mean that more good ideas are generated.

- Look for ways to combine ideas and let ideas build upon each other. This is, of course, more successful if lots of ideas are generated.

- Use visual processes. Creative thinking is often facilitated by drawing pictures and models. As specifically non-linear forms of communication, they help people avoid the disadvantages of thinking only in linear ways.

In short, try not to get stuck in a rut when looking for alternative solutions to the problem that you are trying to solve. Consider the potential need for fresh perspectives and creativity when assembling your decision-making team.

\section{Step 4. Developing and applying decision models and measures}

Many business professionals place great store in their business intuition and argue, often correctly, that their decisions cannot be reduced to simple formulas. But research and professional practice have revealed an increasing number of areas where simple formulas have consistently outperformed the decision-making performance of experienced practitioners. In the introduction to this essay we critiqued the notion of rational decision-making, arguing that observed decision-making behavior seldom conforms to that predicted by the rational decision-making model. Does this observation imply that rational decision-making does not make sense? Not necessarily.

The fact that we may never achieve perfect rationality does not mean that we should not try to be more rational in our decision-making. A spate of books have argued that mathematical analysis can be applied to a much wider variety of problems than previously thought: e.g., Super Crunchers (Ayers, 2007), The Numerati Baker, 2008), Data Driven: Profiting from Your Most Important Business Asset (Redman, 2008), Analytics at Work: Smarter Decisions, Better Results (2010) and How to Measure Anything: Finding the Value of "Intangibles" in Business (2010).

A simple way to think about models is that they identify relationships between elements that have consequences. A simplified model of weight gain is that if we consume more calories than we burn, then we will gain weight. It is a pretty simple model. We can track how many calories we consume, we can estimate, how many calories we burn while performing various types of activities, and then we can make a rough a prediction of how much weight we will have gained or lost. Decision-making models will typically have some type of objective function that the decisionmaking is seeking to maximize or minimize, e.g., weight gain or loss, profits or expenses and some number of predictors. Models can become increasingly complex as we increase the number of predictors, attempt to weight the predictive value of each predictor, and even come up with additional factors that can help us more accurately predict the predictors. We need some ability 
to measure these various elements and the strength of their inter-relationships to use our decisionmaking models.

In this light, we can look at course grades as a type of decision-making model. In one sense, we use course grades as a measure to assess student learning. Students will have completed a variety of assignments, taken exams and participated in class discussions. The instructor grades assignments, exams and participation and calculates the course grade based on the relative weighting of each of these "indicators" of learning. The course grade is thought to be predictor of learning. The instructor used the grades received on individual items to decide what grade to assign for the course. The grade may in turn become part of another mode, e.g., part of the student's gradepoint average used to help a manager predict future student performance on job.

\section{More thoughts on business modeling}

In terms of usefulness, it might be helpful to think about decision models in terms of how well they reduce uncertainty (i.e., improve our predictions) or reduce our chances of error. Let's think of a business example, perhaps a credit card company whose managers want to entice more folks to apply for their cards. They want to do a nationwide mailing, but first they want to decide some things to help ensure they get the best bang for their promotional buck. Should they send the mailers to everyone they can find, or can they develop a list based on population demographics that will increase the number of positive responses? It may cost them more obtain the specialized mailing list. Will the purchase of such a list result in increased number of customers? The company also wants to determine what represents the most cost-effective promotional offer. Should it offer money (we'll add $\$ 50$ to your account), a tangible gift, or a discount on first-year interest rates on the card balance? Businesses must constantly make these kinds of decisions.

Capitol One, a major and very profitable credit card company, conducts more than 30,000 experiments a year designed to help it answer such questions (Davenport, 2006). Capitol One uses the results of its many experiments to construct mathematical models to help get the right credit card offer to the right potential consumer. These models can be very complex, but are not necessarily so.

In his book, The Paradox of Choice: Why More is Less, Barry Schwartz (2006) reports on an experiment at a gourmet food shop which sold a line of specialty jams. The researchers conducted an experiment where a display provided customers the opportunity to sample each of 24 available flavors of jam. On a different day, the display was set up but only offered samples of six flavors. The researchers reported that both displays attracted a lot of attention from customers. Furthermore, customers who visited the two displays sampled an equal number of jams. The interesting finding is that only three percent of the customers visiting the 24-sample display purchased jam. However, 30 percent of the customers exposed to a smaller sample of jams ended up making a purchase. With this little bit of information the retailer would be able to actually sell more jam and waste less. The point of Schwartz's story was to demonstrate the counter-intuitive notion that offering too many choices can actually decrease sales. The significance of this example is that even a small specialty shop can set up an experiment to test alternative sales models that can help it increase its sales. The experiment helped reduce shop owner uncertainty. He or she now had evidence that providing a smaller number of flavors as samples increased sales and incidentally reduced costs.

Hubbard (2010) finds that business professionals often assume that the evidence they need to evaluate their decision models cannot be obtained because they think they cannot measure the things they want to measure or they think making needed measurements will be too expensive. He argues that this is often not the case. With creative thinking, professionals can develop decision models and measures that reduce uncertainty and lead to better decisions. 
We have three concluding thoughts to our discussion regarding business decision models. First, all models include assumptions. Make those assumptions explicit and available for review. Second, do not make your models more complicated than they need to be. Morgan and Henrion (1992, p. xx), authors of the definitive book on decision-making and uncertainty opine:

There are some models, especially some science and engineering, that are large and complex because they need to be. But many more are large or complex because their authors gave too little thought to why and how they were being built and how they would be used.

Kelly Johnson, a former lead engineer at the Lockheed Martin Skunkworks coined the phrase: "Keep it simple, stupid" or KISS. While the phrase was originally used in the context of engineering aircraft so field mechanics would actually be able to repair them, the admonition can be well applied to the design of decision models.

\section{Step 5. Review decision-making performance}

For many years, the U.S. Army has employed After Action Reviews, informally referred to as "hotwashes" to quickly capture lessons learned on whatever endeavor has just been completed. The chief idea is to capture lessons learned while they are still fresh in the participants' minds. What worked; what didn't; what could we do better? This has proven to be an effective management tool and is one that we recommend with respect to improving decision-making performance over time. In business environments, time is almost always a scarce resource. However, investing in evaluating your decision-making performance may pay significant benefits down the line.

\section{Take-aways}

Wow, there is a lot of information in this essay. We think the details are useful, but it is the main ideas that are most important. These are:

- Decision-making constitutes much of the day-to-day activity of business professionals, and evidence suggests that many businesses experience significant decision failures.

- There are a variety of psychological and sociological barriers to effective decisionmaking. Any decision-making process that ignores the potentially negative effects of individual cognitive biases and groupthink increases the probability of producing unsatisfactory results.

- It can be helpful to think of decision-making as a process rather than an event. Doing so allows you to think more rigorously about how the process can be improved.

- While the decision-making process is most easily described as an ordered set of activities, the process is not necessarily linear. You may need to adjust the order of decisionmaking activities and perhaps revisit steps after you think they've been completed.

- Team formation and problem finding are too often neglected in designing decisionmaking processes. Don't make these errors.

- The decision-making process should be designed to promote procedural legitimacy.

- Whether you ultimately rely on qualitative or quantitative data, you need some sort of decision model, the rules that will be applied for selecting an alternative. Even if you are not entirely comfortable with mathematics and statistics, consider the use of quantitative measures; you can usefully measure more than you might first think. 
- Conduct after-decision reviews; reflect on what happened and why to maximize learning from your experience.

We do not want our emphasis on models and measures to imply that we have no respect for creativity and intuition. Creativity and intuition come into play during every step described above. Finally, we acknowledge that many business situations require on-the-spot decision-making where the methods described above are not appropriate. Deciding whether and how much of the process described above is required for the particular decision being made is one of the skills that professionals need to develop.

\section{References}

Ayres, I. (2007). Super crunchers. New York, NY: Bantam Dell.

Baker, S. (2008). The numerati. Boston, MA: Houghton Mifflin.

Carroll, P., \& Mui, C. (2008). Billion dollar lessons: What you can learn from the most inexcusable business failures of the last 25 years. New York, NY: Portfolio.

Davenport, T. H. (2006). Competing on analytics. Harvard Business Review, 84(1), 98-107.

Davenport, T. H., Morison, R., \& Harris, J. G. (2010). Analytics at work: Smarter decisions, better results. Boston, MA: Harvard Business Press.

Hubbard, D. W. (2010). How to measure anything: Finding the value of "intangibles" in business (2nd ed.). Hoboken, NJ: Wiley.

Janis, I. (1982). Victims of groupthink (2nd ed.). Boston, MA: Houghton Mifflin.

Kahneman, D. (2011). Thinking fast and slow. New York, NY: Farrar, Straus and Giroux.

Krakauer, J. (1999). Into thin air: A personal account of the Mt. Everest disaster. Norwell, MA: Anchor.

Janis, I. (1982). Victims of groupthink (2nd ed.). Boston, MA: Houghton Mifflin.

Markus, M. L., \& Keil, M. (1994). If we build it they will come: Designing information systems that people want to use. Sloan Management Review, 35(4), 11-25.

McDonald, A. J., \& Hansen, J. R. (2009). Truth, lies, and O-rings: Inside the space shuttle Challenger disaster. Gainesville, FL: University Press of Florida.

Morgan, M. G., \& Henrion, M. (1992). Uncertainty: A guide to dealing with uncertainty in quantitative risk and policy analysis. Cambridge, UK: Cambridge University Press.

Redman, T. C. (2008). Data driven: Profiting from your most important business asset. Boston, MA: Harvard Business Press.

Roberto, M. A. (2005). Why great leaders don't take yes for an answer: Managing for conflict and consensus. Wharton School Publishing.

Schwartz, B. (2004). The paradox of choice: Why more is less. New York, NY: Harper Perennial. 


\section{Biographies}

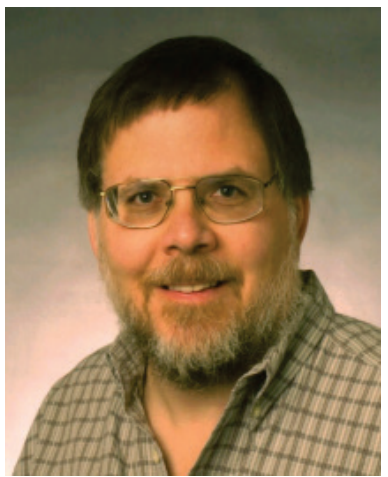

John C. Beachboard joined the Computer Information Systems faculty at Idaho State University in 2001. He completed the Ph.D. in Information Transfer and the M.S. in Information Resources Management at the School of Information Studies, Syracuse University. He holds an M.S. in Business Administration from Boston University and a B.S. in Public Administration from the University of Arizona. Dr. Beachboard has taught the MBA core IT course, and undergraduate courses in IT management and systems, business use of IT, IT architectures, and information assurance. He has held staff and management positions developing, implementing and operating information and telecommunications systems for the Department of Defense. Dr. Beachboard's research interests coincide with his teaching responsibilities and has resulted in the publication of, Peeling the Onion: IT Governance and Management for Business Managers. He services as a subject management expert supporting the US Technical Advisory Group's work on the development and revision of ISO/IEC Standard 20000 IT Service Management .

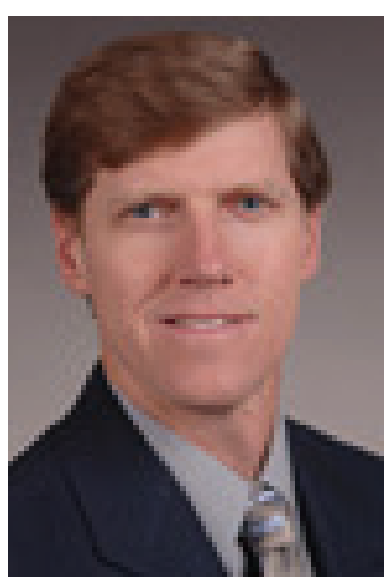

Kregg Aytes is currently Dean of the College of Business at Montana State University. He received his Bachelor's degree in Management Information Systems from the University of Arizona in 1984, at which time he began his career as a Systems Engineer for IBM in Phoenix, Arizona. In 1989, he left IBM to earn his doctorate in Management Information Systems, once again from the University of Arizona. In 1993, Kregg joined the faculty of the College of Business at Idaho State University, where he later served as department chair, Associate Dean, and Interim Dean of the college. In July of 2012, Kregg joined the Montana State University College of Business.

His research interests include information security, collaborative technologies and social media use by entrepreneurs. He also has a strong love of teaching and is interested in the application of IS content and skills across the business school curriculum. 